\title{
DOS FORMAS DE VIDA EN AMERICA
}

I

Cuando el europeo, el hombre de cultura europeo, habla de América, su cultura y sus problemas, suele cometer un equívoco, pensar que América son los Estados Unidos; que su cultura es la llamada cultura norteamericana y sus problemas los problemas que aquejan a esa porción de la América de origen sajón. Este equívoco va lentamente desvaneciéndose en la medida en que la otra América, la. de origen ibero o latino, participa en forma más asidua en las organizaciones internacionales que obligan a un mejor encaramiento de los problemas que aquejan a todos los pueblos del mundo. La cultura en la América Ibera plantea problemas que si bien no son neceśariamente peculiares - esto es, sin conexiones con otras formas de cultura en América, el Occidente o el Mundo en general_, sí son propias de pueblos que se hallan en una situación diversa a la del pueblo que forma la América Sajona.

La América Sajona y la Ibera tienen un origen común: la Cultura Europea u Occidental - como se la llamó a partir de su expansión por el resto del mundo, incluyendo América-. Sin embargo, América entra en la historia de la Cultura Europea u Occidental en una etapa de la misma en que están siendo objeto de revisión sus principios y sus bases. América entra en la historia de esa cultura en una de sus grandes épocas de crisis. América misma, su descubrimiento, conquista y colonización son expresión de esa crisis. Y como en toda etapa crítica, una parte de Europa aboga por un cambio de fundamentos y principios culturales y otra por la permanencia de los que hâsta entonces habían hecho posibles las formas de convivencia y cultura europeas; se acepta, cuando más, una revisión de los mismos, pero no el cambio absoluto, como pretenden los más radicales. Desde luego, no se trata de un antagonismo tan radical que en alguna forma no coincidan los críticos y los defensores de la cultura en crisis. En unos y en otros los aires de la Modernidad se hacen patentes. Los unos y los otros, animados por un nuevo espíritu de aventura se lanzan a descubrir, conquistar y poblar nuevos mundos en los cuales mostrar la bondad de sus respectivos puntos de vista. América se atraviesa en el camino de los unos y de los otros. En ella los partidarios de la Modernidad, los que han hecho del individuo el eje de la reconstrucción propuesta, van a mostrar la certeza de sus puntos de vista. Mientras que los otros, los que aún sostienen los puntos de vista de una comunidad basada en los fines de la Cristiandad, se empeñan, a su vez, en extender esta comunidad a pueblos que hasta ayer eran ajenos a ella.

$$
\text { [125] }
$$


Dos pueblos se presentan en esa etapa como paladines de cada uno de los puntos de vista en conflicto: Inglaterra y España, y con esta última otra porción de la misma, Portugal. La una y las otras llevan su espíritu a la América recién descubierta y la van conformando a su punto de vista hasta dar origen a esas dos expresiones de la Cultura en América que son la sajona y la ibera o latina. Dos porciones de América en ineludible contacto; pero un contacto que da origen a permanentes conflictos e impresiones en los diversos campos de la vida política, económica, social y cultural. Conflictos entre los Estados Unidos de Norteamérica y los div́ersos pueblos a que dio origen la colonización ibera en América. Conflictos en los que se hacen patentes dos formas, de vida que, a su vez, implican dos formas diversas de convivencia que no se ajustan en las ineludibles relaciones de una América con la otra.

Las formas de convivencia de cada una de estas Américas, enraizadas en dos expresiones de la Cultura Occidental, podrian ser encuadradas dentro de la doble clasificación que sobre las formas de convivencia ha establecido el sociólogo alemán Ferdinand Toennies: Comunidad y Sociedad. Clasificación muy general, pero que en muchos aspectos podría corresponder a la que se ha establecido en la llamada América Ibera y la Sajona. Formas de convivencia que en la Cultura Occidental se han expresado en el paso de la Cristiandad a la Modernidad. En este paso, el Racionalismo —-máxima expresión de la Modernidad- desliga la relación causal medio-fin de la convivencia, haciendo de lá convivencia un medió más o menos adecuado a los fines que cada individuo persigue en particular. El Racionalismo subordina las entidades colectivas, las formas de convivencia basadas en un conjunto de intereses que trascienden a los individuales, a otra forma de convivencia que descansa en los intereses concretos de los individuos. En la comunidad los individuos se enlazan, conviven, en función de un fin que los trasciende. En la sociedad cada individuo busca en ella los elementos que han de permitir su propio mejoramiento y la garantía de que sus esfuerzos en pro del bien de la sociedad han "de redundar, a la postre, en su propio bien. Por ello al concepto organicista del Estado medieval se opone el concepto de Estado como producto de un contrato racional, esto es; de dos o más voluntades que se ponen de acuerdo para un fin que beneficia a todas en particular. El Estado moderno es concebido como una sociedäd al servicio de los intereses de los individuos que lo forman. Los hombres, los individuos que forman ese tipo de estado; se han reunido alguna vez y han establecido las bases para formar un Estado, de la misma manera como se han reunido y se reunen grupos de industriales o comerciantes para establecer una determinada sociedad industrial o mercantil.. El Estado, como esas asociaciones comerciales e industriales, no es sino un instrumento más amplio al servicio de los intereses de los individuos. El Estado no es ya el producto de una voluntad natural, 
como la llamaría Toennies; no descansa en una voluntad que trascienda a la de los individuos que lo forman. No existe ya esa voluntad trascendente, religiosa, en que descansaba el orden medieval, la convivencia propia de la Cristiandad.

Los colonizadores iberos en América buscan en el Continente la ampliación del mundo del cual se han hecho paladines en Europa. Su principal preocupación es hacer de esta América otra España o Portugal, esto es, otra Europa Cristiana. Los colonizadores de la América Sajona no, éstos buscan en nuestro Continente una tierra virgen, nueva, sin historia, en la cual cada individuo pueda empezar como si nada estuviera hecho. Una tierra sin compromisos previos, y en la que no se establezcan otros que no sean los que sirvan a los intereses y bienestar de los individuos en concreto. Los iberos traen su mundo, su cultura y formas de convivencia a cuestas; los sajones sus ideas, sus ideales, la imagen del mundo-que quieren crear. Esta diversa actitud se hará patente en las relaciones de unos y de otros con los naturales de América. Unos, subordinándolos, haciéndolos formar parte, por la buena o por la mala, del imperio que representan: el Imperio de los defensores de la Cristiandad. Otros, eliminándolos o convirtiéndolos en simples instrumentos en su afán de aprovechamiento individual. Eliminándolos como animales dañinos o utilizándolos como animales domésticos. $Y$ no es que entre los iberos, especialmente los españoles, no se explotase y asesinase a los indigenas; la diferencia es que para éstos tal acto tenía una sanción moral y religiosa; mientras que para los sajones, de acuerdo con los principios de que eran portadores, el mismo acto carecía de sanción moral o religiosa, por eliminar, previamente, dentro de su concepción de lo humano, a sujetos que carecian de capacidad para aprovechar la naturaleza, para ponerla en su servicio en otra forma que no fuese la puramente natural. No eliminaban o subordinaban a hombres, sino que eliminaban obstáculos naturales difícilmente domesticables, al mismo tiempo que aprovechaban los domesticables.

Pero hay más ; esta misma y doble actitud se va a hacer patente en las relaciones de las dos Américas en sus. ineludibles contactos. En las expresiones culturales de cada una verá la otra la negación de su propio punto de vista. Una, la América Sajona, para afianzarse como expresión máxima del Mundo Moderno; la otra, la ibera, para constatar su incapacidad dentro de un mundo para el cual no fue capacitada. La primera considerándose una representante de la Civilización; la segunda, como conjunto de pueblos al margen de la Civilización, como expresión de lo que el argentino Sarmiento llamaba barbarie, primitivismo. Relaciones en las que una América pretenderá extender sobre otra la civilización que no es otra sino la extensión de los intereses concretos de los individuos que la forman. Mientras la otra trata de frenar esta expansión, que ve crecer día a día, buscando su for- 
talecimiento en la asimilación de la cultura que, en su opinión, ha originado là grandeza de la América del Norte.

A las formas de convivencia apoyadas en la razón que equilibra intereses y establece las bases de la cooperación social que redunde en beneficio de todos y cada uno de sus individuos se le llamó civilización. Mientras recibian el nombre de barbarie las formas de conv́ivencia social de carácter gregario, apoyáda en lazos sanguíneos, de amistad o carismáticos. El Facundo de Domingo F. Sarmiento es uno de los más agudos análisis de esta doble forma de convivencia, de las cuales, la primera pugna por establecerse en la América Hispana; la segunda, por su permanencia. Pugna que Sarmiento hacía descansar en la lucha que se había entablado en la Argentina entre la ciudad y la campiña, Buenos Aires y sus provincias. "En la República Argentina - decía el maestro argentino - se ven a un tiempo dos civilizaciones distintas en un mismo suelo: una naciente, que sin conocimiento de lo que tiene sobre su cabeza, está remedando los esfuerzos ingenuos y populàres de la Edad Media; otra que, sin cuidarse de lo que tiene a sus pies, intenta realizar los últimos resultados de la civilización europea. EI siglo xIx y el siglo xil viven juntos: el uno dentro de las ciudades, el otro en las campiñas." Civilización y barbarie son los extremos entre los cuales se vendrá agitando la vida politica iberoamericana, más concretamente hispanoamericana. La meta, lo que se anhela ser, y lo que se es. La forma de convivencia que se anhela alcanzar, frente a la que se ha heredado. La convivencia apoyada en la razón y la que en último término recurre a la fuerza, a la violencia.

Para cambiar su realidad, las formas de vida heredadas de España y del mundo indígena con el cual ésta se ha mestizado, el hispanoamericano considera la violencia como el más eficaz de los remedios. A la violencia recurre para transformar la realidad que le ha tocado en suerte. Dispuesto a hacer de su mundo un mundo nuevo, moderno, una nación moderna, amputa violentamente su pasado, reniega de la herencia recibida, y se entrega a la tarea de remozar su propio ser, negando lo que ha sido para ser algo completamente distinto: un hombre moderno. $\mathrm{Y}$ en este remozamiento, aunque parezca contradictorio, dispuesto a acabar con un pasado que considera bárbaro, primitivo, actúa con la misma violencia con que actuaria ese bárbaro y primitivo que quisiera dejar de ser. Hombres que alzan su voz contra el primitivismo y la barbarie no se detienen, una vez presentada la oportunidad de lograr lo que consideran su exterminio, en utilizar métodos que mucho tienen de ese primitivismo y barbarie que quieren trascender.

De allí esas extrañas dictaduras para la libertad y la democracia en los países iberoamericanos. Ese hacer de la libertad una obligatoriedad. Ese 
cuerer hacer de los iberoamericanos liberales o demócratas a cualquier precio, incluyendo la más ruda de las violencias. De allí ese espíritu paternalista que se hace patente en los gobiernos iberoamericanos, por liberales y democráticas que sean las doctrinas que sustentan. Si la América Sajona es liberal por naturaleza, la Ibera lo será por la irrebatible decisión y voluntad de los grupos democrático-liberales que se han propuesto esta meta como tarea. $Y$ es en esta actitud, en la violencia aceptada como instrumento de autotransformación, donde sigue radicando ese pasado del que, inútilmente, tratan de desprenderse los hombres que se han empeñado en crear una América nueva, un conjunto de naciones que, a semejanza de las grandes naciones modernas, vengan a ser como adelantados del progreso en sus múltiples formas. Sobre las formas adoptadas como modelo predomina siempre el espíritu de convivencia heredado. Repúblicas federales de nombre, son repúblicas centralistas de hecho. Las voluntades no se unifican en función de una idea o ideal sino como partes de una voluntad más férrea. El caudillismó, cuando es uno, unifica voluntades; cuando son varios, atomiza esfuerzos y produce la violencia. Una violencia en la cual han de predominar, siempre, los mejores; no por sus cualidades morales, sino por su fuerza para abatir voluntades opuestas. Por su capacidad para unificar una sociedad que sin esa fuerza caería en la anarquía. Anarquía que representá lá otra cara de la medalla. Anarquía que nada tiene que ver con la libertad que han establecido las naciones modernas que sirven de modelo a los pueblos hispanoamericanos. Por ello ese maestro de maestros que fue Andrés Bello decía: "Arrancamos el cetro al monarca, pero no al espíritu español: nuestros congresos obedecieron, sin sentirlo, a inspiraciones góticas. .. hasta nuestros guerreros adheridos a un fuero especial, que está en pugna con el principio de la igualdad ante la ley, revelan el dominio de las ideas de esa misma España cuyas banderas hollaron".

En los esfuerzos que realiza el hispanoamericano para pasar de lo que considera su primitivismo al civilismo de las naciones modernas, se hace patente ese espíritu que vanamente trata de negar. "El gobierno del pueblo, por el pueblo y para el pueblo" que representa el ideal democrático y liberal de los pueblos anglosajones que sirven de modelo a la América Ibera, se convierte en un ideal a realizar con independencia de la voluntad de ese pueblo. Una voluntad que, se considera, no puede ser tomada en cuenta en una tarea para la cual no está aún preparada, formada. El gobierno del pueblo, para el pueblo y por el pueblo, debe ser realizado en los países de la América Ibera a pesar del pueblo mismo. Porque este pueblo, si expresa libremente su voluntad, no podrá expresar otra cosa que el punto de vista, el espiritu, que le fue impuesto en largos siglos de colonización. Su voluntad lejos de expresarse a sí misma, expresará la voluntad de un mundo que es la negación de su autonomía, de su libertad. De allí ese otro ángulo tan importante en la historia de la América Ibera, la educación. 
Sólo educando, formando a los iberoamericanos en los principios que hacen de las comunidades entidades civiles, se podrá hacer de los mismos hombres libres, demócratás, capaces de realizar esa forma de gobierno en que el pueblo es principio o fin. No antes. Antes nó podrá hacerse otra cosa que obligar al pueblo a seguir el camino de su propia liberación. Le guste o no le guste, esté de acuerdo o no, en relación con el espíritu colonial en que ha sido formado, el pueblo ha de seguir el camino que conduce al liberalismo y la democracia que han hecho la grandeza de los pueblos modernos. Los mismos métodos que han servido para mantener a los pueblos en la ignorancia y la servidumbre, han de servir para educarlos y liberarlos. De alli esos aparentes contrasentidos como el de la óbligatoriedad de la educación liberal que aún se hace patente en los gobiernos liberales de nucstra América. Gobiernos liberales que, a su vez, no tienen empacho en actuar en forma casi dictatorial o paternalista. Gobiernos federales en su forma que son centralistas en su actuación. Gobiernos cuya meta es hacer que sus pueblos lleguen a alcanzar esa autodeterminación que ha hecho posible las auténticas democracias. Una meta que, desgraciadamente en muchos de nuestros pueblos, tarda en alcanzarse y, a veces, es "negada. Meta con la cual muchas dictaduras hispanoamericanas de nuestros días tratan de justificarse. Educación obligatoria para la libertad y gobierno paternalișta o dictatorial para la democracia, son peligrosas formas que han adoptado los países iberoamericanos en su difícil marchà para incorporarse a un mundo para el cual no habían sido formados como los sajones. Es más, un mundo al cual tenían, ineludiblemente, que incorporarse dada la acción expansiva del mismo. Un mundo que, al expandirse, hacia los pueblos no preparados para el mismo, los iba transformando en un nuevo tipo de colonias. De allí la urgencia y, con ella, los métodos de transformación que la misma imponía. Uno era la idea, el proyecto, lo que se quería ser; y otro lo que se era, lo que era menester transformar.

De esta difícil combinación habrán de surgir los problemas que han aquejado a los pueblos en la América Ibera y que nunca aquejaron a la América Sajona. De aquí también esas formas tan diversas de convivencia en una y en otra América. La sajona, desarrollando en su forma natural formas que le eran propias; la ibera obligada a" combinar el mundo de que era heredera con el mundo que aspiraba a realizar. Ya lo decía también Bello al referirse a esa difícil combinación entre lo ideal y, lo real que trató de obtener el hispanoamericano desde los inicios de su emancipación política. "En nuestra revolución, la libertad era un aliado extranjero que combatía bajo el estandarte de la independencia y que, aún después de la victoria, ha tenido que hacer no poco para consolidarse y arraigarse." Un mundo extraño, nuevo, para el hispanoamericano, tratando de realizarse con materiales que parecían serle ajenos, hasta contrarios, opuestos. "La obra de los guerreros está consuma- 
da -seguía diciendo Bello-; la de los legisladores no lo estará mientras no se efectúe una penetración más íntima de la idea imitada, la idea advenediza, en los duros y tenaces materiales ibéricos."

\section{III}

¿Cuáles eran estos duros y tenaces materiales ibéricos que tanta resistencia oponian a las ideas adoptadas? $O$ sea, ¿qué es lo peculiar al mundo ibero? Este algo es lo que muchos estudiosos de la historia de nuestra cultura han llamado el individualismo de esos pueblos. Sin embargo, también se habla de individualismo entre los pueblos sajones. El individualismo, asi, sin mayores explicaciones, parece algo común a los colonizadores y sus descendientes en las dos Américas. Pero no hay tal, el individualismo entre los sajones es distinto del seguido por los iberos. Tan distintos que van a dar origen a dos formas de cultura bien diversas. Es el individualismo, en la forma como lo hace patente el anglosajón, el que ha dado origen a las instituciones liberaldemocráticas que caracterizan a la América Sajona; no así el individualismo ibero que, por el contrario, ha impedido o dificultado su realización en la otra América.

En la América Sajona el individuo ha tejido el conjunto de relaciones sociales necesarias para alcanzar una relativa seguridad. Esa seguridad que tanto necesita para dedicarse exclusivamente al logro de los bienes en los cules finca su felicidad. Para el logro de esta seguridad el individuo cede un mínimo de su libertad, a fin de alcanzar, a cambio de esa libertad cedida, un máximo de seguridad. Lo importante es aquí la defensa y seguridad 'de los estancos que representa cada individuo como miembro de la sociedad. Una sociedad, ya se ha visto, cuya meta es el individuo mismo. Entre los pueblos de origen ibero la individualidad tiene otro sentido: el de personalidad. Aquí lo que importa es destacarse sobre los otros, hacer de los propios fines los de los otros. El individuo, lejos de respetar los estancos de los otros individuos, se extiende, crece, en ellos. Los otros se extienden a su vez, haciendo de los fines que ellos persiguen sus propios fines. De esta manera unos y otros se complementan y dan origen a esas formas de convivencia que hemos llamado comunidades. Expresión de este tipo de convivencia propia de los pueblos iberos es el caudillaje. Caudillajes que son como el polo opuesto de las instituciones liberal-democráticas de los anglosajones.

Caudillos, jefes o directores existen y han existido en ambas Américas; lo que cambia es la función que juegan los mismos en ellas. Entre los anglosajones se reconoce únicamente como caudillo a aquel individuo capaz de alcanzar para la sociedad a que pertenece un mayor número de ventajas sociales, políticas o económicas; ventaja cuyos beneficiarios serán siempre 
los individuos concretos que forman esa sociedad. No sucede lo mismo entre los iberos; entre éstos lo importante es la personalidad capaz de unificar esfuerzos hacia no importa' que metas. La seguridad, la existencia, todas las ventajas posibles, se las puede jugar el ibero por una de. estas metas de los demás. Por 'ello entre los sajones los caudillos sólo tienen un carácter circunstancial, a diferencia de los iberos, que parecen necesitarlos permanentemente. Entre los anglosajones sólo aparecen los caudillos cuando la seguridad y la posibilidad de ampliación de los intereses de la sociedad están amenazadas. Si esta amenaza no se hace patente los individuos que forman las sociedades anglosajonas se bastan a sí mismos para mantener la seguridad necesaria que permitá la ampliación de sus intereses.' No sucede 'Io mismo entre los iberos, que parecen, como ya se dijo, necesitar del caudillaje como un estímulo permanente. Entre éstos no tiene sentido esa autolimitación que no tenga más meta que la seguridad del estanco individual. Por ello, cuando falta este estímulo aparece la anarquía, la pugna entre individuos que no están dispuestos a limitar sus intereses ante personalidades que no trasciendan la suya.

El brasileño Sergio Buarque de Holandá, al hablar de las raíces de los pueblos que forman la América Ibera, se refiere a' esa peculiaridad de su individualismo llamada personalidad. Ninguno de los pueblos vecinos a los iberos, dice, "sabe desarrollar a tal extremo ese cultivo de la personalidad que parece constituir el rasgo más decisivo en la evolución de la gente hispánica, desde tiempos inmemoriales". Esa peculiaridad descansa en "la especial importancia que atribuyen al valor propio de la persona humana". y en la "autonomía de cada uno de sus hombres en relación con sus semejantes en el tiempo y en el espacio". Entre sí, cada uno de estos individuos se sabe independiente, ajeno, un igual entre iguales que no tiene por qué limitar su libertad. El indivîduo se siente capaz de prescindir de los demás; por ello, la sociedad, como la entienden los anglosajones, la sociedad moderna, es casi. imposible entre iberos que consideran cualquier servicio como disminución de la propia personalidad. La "arrogancia", dice Buarque de Holanda, es el concepto que mejor hace patente este sentimiento. Indice de lucha y emulación; pero al mismo tiempo fuente de flaquezas. "A esto se debe - dice- la singular flaqueza de las formas de organización que impliquen solidaridad y orden entre dichos pueblos. En una tierra donde todos son barones no es posible llegar a un acuerdo colectivo y duradero, a no ser por una fuerza exterior respetable y temida." Esta fuerza puede ser material; pero también puede ser moral la que hace posibles los caudillajes; caudillajes que, a su vez, se transforman fácilmente en dictaduras de fuerza. Los caudillajes y dictaduras que parecen caracterizar a las formas de convivencia social de nuestros pueblos en la América Ibera. 
'El individualismo anglosajón, con su preocupación en torno a la seguridad y posibilidad de ampliación de intereses de los individuos que forman la sociedad irá dando lugar, aunque parezca una paradoja, a sociedades que, a fuerza de cuidar de esa seguridad que las ha hecho posibles van reduciendo la libertad de sus miembros. La autolimitación, necesaria para el logro de la seguridad que permite la ampliación de los intereses de los individuos que la realizan, se va ampliando e invadiendo terrenos cada vez más personales, tal y como se hace patente en muchas de las expresiones de la vida cultural, social, política y económica de la América del Norte. Las sociedades modernas, a fuerza de prever para servir, a fuerza de anticiparse en la solución de los problemas que se presentan o pueden presentarse a sus miembros, van limitando la libre espontaneidad de los mismos. El individuo, en estas sociedades, se va moviendo dentro de cuadros de acción cada vez más estrechos. Poco a poco, se va transformando en una especie de autómata. La seguridad, en la medida en que crece, limita más y más la espontaneidad de los asegurados. A fuerza de limar las asperezas de la convivencia, señalando a cada individuo el estanco dentro del cual'su acción encontrará menos roces, va transformando a éste en pequeñas piezas del colosal engranaje de una gran maquinaria, cada vez más poderosa, cuya meta trasciende los anhelos de los individuos que la forman. La libertad, como capacidad de actuar de otra manera que la prevista; va quedando cada día más limitada. Cada día tiene menos sentido lo imprevisto, la improvisación o el gesto inútil y gratuito, hasta ahora fuente de toda actividad creadorá.

Obra del individualismo moderno, la maquinaria que hace posibles las sociedades modernas, va limitando a éste. Tal hecho se va haciendo patente en diversas expresiones de cstas sociedades. Poco a poco el individuo va siendo desplazado en una sociedad en que todas las posibilidades de su acción van siendo calculadas. Las grandes estadísticas van haciendo previsible su acción y, con ella, la orientación de la misma. La sociedad moderna se va transformando en un conjunto de sociedades anónimas en las que todo to que de concreto forma a un individuo va desapareciendo. Sociedad que en nuestros días calcula, fríamente, hasta el desgaste humano que es necesario para la seguridad anhelada. ¿Seguridad para quién? Poco a poco se va perdiendo este quién o alguien concreto. Dentro del cálculo que se realiza para atender a la seguridad se van perdiendo las relaciones concretas. De acuerdo con el mismo se habla ya de la necesidad de limitar no sólo la libertad, sino la existencia de determinados individuos para el logro de la seguridad de otros. ¿Cuáles? No importa concretizar. Sólo se habla, en general, de clases, razas, pueblos o naciones destinados por $x$ razones al sacrificio o a la seguridad. El individuo concreto se va perdiendo en esas generalidades. 
Frente a este mundo está el que forman aún comunidades primitivas como las iberoamericanas. Un mundo casi primitivo, inseguro, en el que cada individuo se ve obligado a luchar por su seguridad limitando la de otros o descansando en la que los mejores puedan ofrecerle. Mundo inseguro, lleno de zozobras. Un mundo en que las relaciones de convivencia tienen aún su origen en formas primitivas de parentesco o amistad. Sociedad sin ciudadanos; comunidad, más o menos amplia, de parientes o amigos. Sociedad en que se busca eludir cualquier formalidad que impida esa relación directa, concretá, entre individuos. Sociedad cuyas leyes y legislaciones no hacen sino encubrir situaciones de hecho que han sido originadas por voluntades concretas. Sociedad en la cual la maquinaria burocrática es casi siempre eludida por esa institución tan característica en los pueblos iberoamericanos, la "coima" o la "mordida", como la llaman en México. Institución que permite el ajuste concreto de las relaciones entre el individuo y la sociedad. Dentro de esta sociedad la ciudadanía adquiere un carácter personal, de relación entre personas concretas. No hay funcionarios encargados de vigilar el orden social, sino individuos concretos con los cuales es importante tener una relación concreta de amistad, parentesco o conócimiento. Por esto en los pueblos iberoamericanos no importa tanto el programa de sus gobiernos, como la relación que los miembros del mismo tengan con sus electores. 0 - seguidores. Importa mucho, por ejemplo, ser amigo del Presidente de la República, sus ministros o cualquiera de sus funcionarios; o al menos, amigo de sus amigos; o amigo de los amigos de sus amigos en una cadena en que siempre se busca la relación personal. Una cadena sin fin que bien puede abarcar a todos los miembros de una comunidad iberoamericana.

Tipo de sociedad, esto es, comunidad, que siendo la fuente de todos los males que aquejan a los pueblos iberoamericanos, puede ser al mismo tiempo el punto de partida para un tipo de convivencia más humano que ése en que han ido cayendo las sociedades modernas. Ese tipo de comunidad que alguna vez se ha apuntado como pósibilidad en las mejores etapas de lá historia de los pueblos iberoamericanos. Una comunidad que ligue a los hombres con los hombres y no con entidades abstractas. Comunidad en que los individuos, a fuerza de saberse personales y únicos, sepan también que son los únicos y personales responsables de su acción en relación con los demás y consigo mismos. Sentido de responsabilidad comunal por la que el individuo pueda acrecentar su personalidad hasta confundirla con la comunidad a que pertenece; como si cada individuo fuese al-mismo tiempo la parte y el todo de la misma. Este tipo de convivencia, a pesar de todos sus defectos, a pesar de los frutos a que ha dado origen, ya ha hecho posibles relaciones de humanidad más justás. El chileno Francisco Bilbao, aceptando las cualidades de la civilización anglosajona, no dejaba, por esto, de señalar su diferencia y limitaciones frente a lo que la herencia ibera tenia de positivo. "El libre 
pensamiento, el self-government, la franquicia moral y la tierra abierta al inmigrante - decía-, han sido las causas de su engrandecimiento y de su gloria." En los Estados Unidos todo ha crecido, "riqueza, población, poder y libertad"; pero también ha crecido la ambición de este pueblo que no ha podido ver a otros pueblos como sus iguales o semejantes. Los Estados Unidos, de acuerdo con ese sentido de convivencia que les es propio, no han podido ver en otros pueblos $u$ hombres otra cosa que lo que los mismos tienen de aprovechable, de útil; o de obstáculo. Preocupados por su seguridad y por ampliar los bienes en los que fincan su felicidad, sólo se han preocupado por establecer vallas defensivas o por romper las que los obstaculizan sin incorporar, por esto, a los individuos que detrás de ellas se encuentran. Actitud muy distinta a la de los pueblos de origen ibero que ampliaban su personalidad incorporando a ella a otros pueblos $\mathbf{u}$ hombres. Por ello los Estados Unidos, dice Bilbao "no abolieron la esclavitud de sus estados, no conservaron las razas heroicas de sus indios, no se han constitùido en campeones de la causa universal, sino del interés americano, del individualismo sajón". Por ello "se precipitan sobre el sur". En cambio, en el sur, en la América Ibera, a pesar de su herencia, a pesar de la España teocrática que lleva dentro, ha habido "luz en las entrañas del dolor, y rompimos la piedra sepulcral". Los iberoamericanos, a diferencia de los anglosajones, han tenido que crear y organizar todo desde sus inicios. "Hemos tenido que consagrar la soberania del pueblo en las entrañas de la educación teocrática." Pero a pesar de todos los obstáculos, dice Bilbao, "hemos hecho desaparecer la esclavitud de todas las repúblicas del sur...; hemos incorporado e incorporamos a las razas primitivas... porque las creemos nuestra sangre y nuestra carne, mientras vosotros las exterminais jesuíticamente". Nosotros "no vemos en la tierra, ni en los goces de la tierra, el fin definitivo del hombre; el negro, el indio, el desheredado, el infeliz, el débil, encuentran en nosotros el respeto que se debe al título y a la dignidad del ser humano". "He aqui lo que los republicanos de la América del Sur se atreven a colocar en la balanza, al lado del orgullo, de las riquezas y del poder de la América del Norte." Pues bien, ese espíritu, esa capacidad del iberoamericano para incorporarse a sus semejantes en otro plano que el simplemente utilitario, era propio de esa herencia que en vano trataba arrancarse. No todo era negativo en el espíritu que animaba a las comunidades iberas; algo, mucho, había en ellas que les había permitido triunfar contra sí mismas; algo que no poseían los pueblos cuyas instituciones les servían de modelo. "El que observe con ojos filosóficos la historia de nuestra lucha contra la metrópoli —decía Belloreconocerá sin dificultad que lo que nos ha hecho. prevalecer sobre ella es cabalmente el elemento ibérico. La nativa constancia española se ha estrellado contra sí misma en la ingénita constancia de los hijos de España." La España joven vencía a la vieja España conservando "el aliento indomable de 
la antiguà defensa de sus hogares". Lo nuevo fue el espíritu republicano, que no había podido sèr enseñado por la España feudal; pero algo "había de magnanimidad, de heróismo, de altiva y generosa independencia" en los hombres que lucharon por realizar esa nueva idea, ese heroísmo, altivez, generosidad e independencia propios de los hombres que descubrieron, cònquistaron y'colonizaron la América Iberá.

LeOPOLdo ZeA 